\title{
Studies of the species barrier between Drosophila subobscura and $D$. madeirensis. III. How universal are the rules of speciation?
}

\author{
MAHNAZ KHADEM \& COSTAS B. KRIMBAS \\ Department of Genetics, Agricultural University, lera Odos 75, Votanicos, 118-55 Athens, Greece
}

\begin{abstract}
The prevalence of Haldane's rule and the large effect of the $\mathrm{X}$ chromosome are examined by analysing the genetics of seven abnormal characters in interspecies hybrids between $D$. subobscura and $D$. madeirensis. In two cases Haldane's rule is not obeyed (viability and abnormality of the head). In all characters except the abnormal abdominal tergites, an important effect of the $\mathrm{X}$ chromosome is observed. There is an asymmetry in the importance of the effect of the $\mathrm{X}$ chromosome. The $\mathrm{X}$ of $D$. madeirensis origin induces abnormality mostly in a mixed background. The Y chromosome plays an important role in determining male sterility.
\end{abstract}

Keywords: Drosophila, Haldane's rule, hybrid abnormality, hybrid sterility, hybrid viability, sex chromosomes.

\section{Introduction}

Interspecific hybrids provide a good opportunity to study the process of speciation, providing that at least some of the $\mathrm{F}_{1}$ hybrids are fertile and viable. During the last decade, following the pioneering work of Dobzhansky (1936), we have witnessed a slowly growing number of genetic analyses of species differences (Coyne, 1984, 1985; Vigneault \& Zouros, 1986; Lumme \& Heikken, 1990; Khadem \& Krimbas, 1991a), which has been accompanied by theoretical advances (Zouros, 1986; Charlesworth et al., 1987; Coyne \& Orr, 1989; Frank, 1991a; Read \& Nee, 1991).

Generally it is believed that two rules are held in interspecific hybridization (Coyne \& Orr, 1989):

1 It is generally the heterogametic sex that suffers most from sterility/inviability (Haldane's rule) (Haldane, 1922);

2 The X chromosome has a disproportionate effect compared to that of the autosomes on hybrid sterility/ inviability. The large effect of the $\mathrm{X}$ chromosome was observed for both sexes in all the cases that have been studied (Dobzhansky, 1936; Patterson \& Griffen, 1944; Coyne, 1984, 1985; Orr, 1987, 1989; Khadem \& Krimbas, 1991a). Although the mainstream of the theoretical generalization is in support of the rules (Coyne et al., 1991; Frank, 1991b) the significance of Haldane's rule has been questioned by some authors (Read \& Nee, 1991). On the other hand, among the opponents of the rule there is disagreement as to its causation (Coyne et al., 1991; Frank, 1991a). In the present paper we report on the prevalence of Haldane's rule, the role of the sex chromosomes and of the maternal effect in the genetic analysis of seven different characters in the hybrids between Drosophila subobscura and Drosophila madeirensis: (i) female fertility; (ii) testes size; (iii) sperm motility; (iv) viability; (v) extra sex combs; (vi) abnormal head shape; (vii) abnormal abdominal tergites. Hybrid male sterility, extra sex combs and abnormal head shape have been examined in detail only in one type of cross, i.e. $F_{1}$ females from madeirensis mother crossed to male subobscura (Khadem \& Krimbas, 1991a,b). Extra sex combs have been also analysed by Papaceit et al. (1991) in the same type of cross. All the characters are included again in the present study, because for the first time we were able to analyse them in all the crosses. Does the same mechanism(s) also hold in the case of the reciprocal cross?

\section{Materials and methods}

\section{Strains}

One strain of vermilion flies was used. Vermilion (ve) is a marker on the $\mathrm{X}$ chromosome of Drosophila subobscura. As the originally described vermilion is lost we were unable to perform allelism tests between the two vermilion strains. Our strain was constructed 
from a cross between $D$. madeirensis females and $D$. subobscura males; the mutation occurred spontaneously in the backcross males. These males were sterile so their female sisters were crossed to $D$. subobscura males for seven generations. Therefore the strain was cleansed of D. madeirensis material and consists mainly of $D$. subobscura chromosomes, except for one cytological marker on the $E$ chromosome that remains polymorphic. All the characteristics of the strain are those of D. subobscura (small body size, dark body colour, dark antennae, number of the sex combs' teeth). (The vermilion strain is called $D$. subobscura throughout this paper.) Another marker, also located on the $\mathrm{X}$ chromosome, controls the colour of the antennae (Khadem \& Krimbas, 1991a). A single strain of Drosophila madeirensis was used. This species has light coloured antennae; the colour being darker in females.

\section{Crosses}

Two reciprocal crosses were performed:

1 D. madeirensis females were crossed to D. subobscura males and the $\mathrm{F}_{1}$ females were backcrossed to either of the parental species.

$2 D$. subobscura females were crossed to $D$. madeirensis males and the $F_{1}$ females were backcrossed to either of the parental species.

The single strain of $D$. madeirensis, used in the present study, differs from the two strains that were used in our previous work (Khadem \& Krimbas, 1991a,b). Using the new strain we were able to perform the cross between $D$. subobscura females and $D$. madeirensis males and obtain fertile and viable female progeny. Further explanations are given later in the text.

\section{Abbreviations}

The abbreviations mad and $s u b$ are sometimes used instead of $D$. madeirensis and $D$. subobscura. The origin of the maternal species is specified in brackets, for example $F_{1}[\mathrm{mad}]$. The crosses are all between $F_{1}$ females and males of the two parental species, therefore the male sign is dropped. Thus $F_{1}[\mathrm{mad}] \times \operatorname{mad}$ indicates a backcross between $F_{1}$ females (from mad females and sub males) to mad males.

\section{Results}

\section{Female sterility}

A female was considered sterile when each of the ovaries had only one or no ovariole, semi-normal when they had between two and five ovarioles and normal when they had more than five ovarioles. Semi-normal females are considered fertile. In Tables 1 and 2 the numbers of parental, $F_{1}$ and $B_{1}$ females of each category are given.

The results show that a combination of $\operatorname{madX} / \mathrm{subX}$ has a significant effect on the sterility of the females, when the original mother is madeirensis. A madeirensis $\mathrm{X}$ chromosome, combined with some foreign autosomal factor(s), fares better in foreign cytoplasm than in its own cytoplasm. A significant difference is also detected when the female progeny of $F_{1}[\mathrm{mad}] \times$ mad and $\mathrm{F}_{1}[\mathrm{sub}] \times \operatorname{mad}$ or $\mathrm{F}_{1}[\mathrm{mad}] \times$ sub and $\mathrm{F}_{1}[$ sub $] \times$ sub are compared $\left(\chi^{2}=53.3\right.$ and 18.9 , respectively for 2 d.f., $P<0.001)$. This is a strong indication of the importance of the maternal effect in determining female sterility in both the $\mathrm{F}_{1}$ and the backcross females.

\section{Testes size}

$\mathrm{F}_{1}$ males from a madeirensis mother have testes of almost normal size (67 normal, 3 one normal + one small testis and 4 small). When the mother is subobscura, about half of the $F_{1}$ males have normal or almost normal and the other half have small testes ( 33 normal -36 small). The difference between the two reciprocal crosses is significant $\left(\chi^{2}=37.36\right.$ for 1 d.f., $\left.P<0.001\right)$. Note, however, that the results in this second cross vary greatly from one repetition to another, and thus the difference between the two crosses should be treated with some caution.

From Tables 3 and 4 it is clear that in all possible crosses, the compatibility of the sex chromosomes leads almost always to individual backcross males with normal testes size. On the other hand incompatibility of the sex chromosomes always results in small and empty testes. There are some exceptional cases, which are marked with an asterisk on the left of the Tables. The exceptional cases are 20 out of 304 and 8 out of 222 in Tables 3 and 4, respectively.

\section{Sperm motility}

In general, males with testes of normal size have sperm and the ones with small testes do not. However, sperm can be either motile or immotile. Males with motile sperm are considered to be fertile (regardless of the percentages of their motile sperm). Sterile males are the ones that either do not have any sperm or their sperm is immotile. When the sex chromosomes are compatible, about half of the backcross males with subcytoplasm and two-thirds with mad cytoplasm are fertile (see Tables 3 and 4). 
Table 1 Number of sterile (S), semi-normal (S-N) and normal $(\mathrm{N})$ females in parental species, $F_{1}$ hybrids and hybrid backcrosses

\begin{tabular}{llrrrrl}
\hline Generation & Cross & S & S-N & N & $\chi^{2}(2$ d.f. $)$ & Percentage $\dagger$ \\
\hline$P$ & mad & 9 & 18 & 87 & & 8 \\
$\mathbf{P}$ & sub & 0 & 7 & 53 & & 0 \\
& & & & & $6.61^{*}$ & \\
$\mathrm{~F}_{1}$ & {$[\mathrm{mad}]$} & 8 & 0 & 20 & & 29 \\
$\mathrm{~F}_{1}$ & {$[\mathrm{sub}]$} & 6 & 12 & 20 & & 16 \\
& & & & & $10.66^{* *}$ & \\
$\mathrm{~B}_{1}$ & $\mathrm{~F}_{1}[\mathrm{mad}] \times \operatorname{mad}$ & 73 & 19 & 24 & & 63 \\
$\mathrm{~B}_{1}$ & $\mathrm{~F}_{1}[\mathrm{mad}] \times \mathrm{sub}$ & 65 & 27 & 55 & & 44 \\
& & & & & $10.53^{* *}$ & \\
$\mathrm{~B}_{1}$ & $\mathrm{~F}_{1}[\mathrm{sub}] \times \mathrm{mad}$ & 28 & 8 & 79 & & 24 \\
$\mathrm{~B}_{1}$ & $\mathrm{~F}_{1}[\mathrm{sub}] \times \mathrm{sub}$ & 9 & 6 & 38 & & 17 \\
& & & & & 2.25 & \\
\hline
\end{tabular}

mad $=D$. madeirensis, sub $=D$. subobscura, $\mathrm{F}_{1}[\mathrm{mad}]$ is from mad females crossed to sub males, $F_{1}\left[\right.$ sub] is from sub females crossed to mad males. $F_{1}$ females of the two kinds are crossed to mad or sub males.

$\dagger$ The percentage of sterile females is given in the last column.

Each chi-square test examines homogeneity of the progeny for the two associated crosses. ${ }^{*} P<0.05,{ }^{* *} P<0.01,{ }^{* * *} P<0.001$.

Table 2 Number of sterile ( $\mathrm{S}$ ), semi-normal (S-N) and normal $(\mathrm{N})$ backcross females classified according to the origin of their $\mathrm{X}$ chromosomes. Chi-square tests examine the significance of the effect of the $\mathrm{X}$ chromosome in determining female sterility

\begin{tabular}{llllllll}
\hline Generation & Cross & X origin & S & S-N & N & $\chi^{2}$ (2 d.f.) & Percentage \\
\hline $\mathrm{B}_{1}$ & $\mathrm{~F}_{1}[\mathrm{mad}] \times$ sub & $\operatorname{madX} / \mathrm{subX}$ & 47 & 6 & 13 & 71 \\
& & subX/subX & 18 & 21 & 42 & 22 \\
& & & & & $36.16^{* * * *}$ & \\
$\mathrm{~B}_{1}$ & $\mathrm{~F}_{1}[$ sub $] \times$ sub & $\operatorname{madX/subX}$ & 7 & 2 & 18 & 26 \\
& & subX/subX & 2 & 4 & 20 & 8 \\
& & & & & 3.52 & \\
\hline
\end{tabular}

See footnote to Table 1 for definition of crosses and percentage.

${ }^{*} P<0.01,{ }^{* *} P<0.01,{ }^{* * *} P<0.001$.

\section{Viability}

Female viability is compared to male viability in $F_{1}$ and backcross generations (viability is measured by the number of emerged flies). $F_{1}$ progeny from a madeirensis mother have a normal sex ratio and those from a subobscura mother an abnormal sex ratio (Table 5). In an earlier work this cross was reported to produce an extreme sex ratio in favour of the males (Khadem \& Krimbas, 1991a; Papaceit et al., 1991). Our current results differ from those in an earlier work, in the sense that the ratio of the females to males increased signifi- cantly. It varies from $1: 2$ to $1: 1$ in different performances of the same cross. Preliminary experiments indicate that the stock of $D$. madeirensis used in the present work is the cause of the increased number of females in the $F_{1}$ generation.

Lower viability is also observed in the case of backcross females of $F_{1}[$ sub] $\times$ mad (Table 5 ). It is possible that some chromosomal factor(s) of madeirensis, including those of the $\mathrm{X}$ chromosome, interact with the subobscura cytoplasm causing this inviability. We cannot be more specific about females' viability because in some crosses we were unable to distinguish madX/ 
Table 3 Testis size and the presence or absence of sperm in backcross males. All individuals have madeirensis cytoplasm and different combinations of $\mathrm{X}$ and $\mathrm{Y}$ chromosomes. The origin of the $\mathrm{X}$ chromosome is detected by eye and antennae colour. The origin of $\mathrm{Y}$ is known from the type of backcross. Incompatible combinations are those bearing $\mathrm{X}$ and $\mathrm{Y}$ from a different origin and they display small testes, usually empty. Exceptions to this rule are indicated by an asterisk $\left({ }^{*}\right)$ on the left of the table

\begin{tabular}{|c|c|c|c|c|c|c|c|}
\hline $\begin{array}{l}\text { Eye } \\
\text { colour }\end{array}$ & $\begin{array}{l}\text { Antennae } \\
\text { colour }\end{array}$ & $X$ & $\mathrm{Y}$ & $\begin{array}{l}\text { Testis } \\
\text { size }\end{array}$ & Motility & $n$ & Inc. \\
\hline \multicolumn{8}{|c|}{$\mathbf{F}_{1}[\mathrm{mad}] \times \mathrm{mad}$} \\
\hline * ve & Dark & sub & $\operatorname{mad}$ & Normal & Immotile/absent & 9 & Yes \\
\hline ve & Dark & sub & $\operatorname{mad}$ & Small & Absent & 78 & Yes \\
\hline *ve & Light & $\mathrm{sub} / \mathrm{mad}$ & $\operatorname{mad}$ & Small & Absent & 7 & Yes/no \\
\hline+ & Light & $\operatorname{mad}$ & $\operatorname{mad}$ & Normal & Motile & 37 & No \\
\hline+ & Light & $\operatorname{mad}$ & $\mathrm{mad}$ & Normal & Immotile & 19 & No \\
\hline \multicolumn{8}{|c|}{$\mathrm{F}_{1}[\mathrm{mad}] \times$ sub } \\
\hline$*+$ & Light & $\operatorname{mad}$ & sub & Normal & Immotile/absent & 9 & Yes \\
\hline+ & Light & $\operatorname{mad}$ & sub & Small & Absent & 38 & Yes \\
\hline ve & Dark & sub & sub & Normal & Motile & 65 & No \\
\hline ve & Dark & sub & sub & Normal & Immotile & 40 & No \\
\hline * ve & Dark & sub & sub & Small & Absent & 2 & No \\
\hline
\end{tabular}

$n=$ number of flies examined, Inc. $=$ incompatibility of the sex chromosomes.

Table 4 Testis size and the presence or absence of sperm in backcross males. All individuals have subobscura cytoplasm and different combinations of $\mathrm{X}$ and $\mathrm{Y}$ chromosomes. The origin of the $\mathrm{X}$ chromosome is detected by eye and antennae colour. The origin of $\mathrm{Y}$ is known from the type of backcross. Incompatible combinations are those bearing $\mathrm{X}$ and $\mathrm{Y}$ from a different origin and they display small testes, usually empty. Exceptions to this rule are indicated by an asterisk $\left({ }^{*}\right)$ on the left of the table

\begin{tabular}{|c|c|c|c|c|c|c|c|}
\hline $\begin{array}{l}\text { Eye } \\
\text { colour }\end{array}$ & $\begin{array}{l}\text { Antennae } \\
\text { colour }\end{array}$ & $\mathrm{X}$ & $\mathrm{Y}$ & $\begin{array}{l}\text { Testis } \\
\text { size }\end{array}$ & Motility & $n$ & Inc. \\
\hline \multicolumn{8}{|c|}{$\mathrm{F}_{1}[\mathrm{sub}] \times \mathrm{mad}$} \\
\hline *ve & Dark & sub & $\operatorname{mad}$ & Normal & Absent & 2 & Yes \\
\hline ve & Dark & sub & $\operatorname{mad}$ & Small & Absent & 50 & Yes \\
\hline$*$ ve & Light & $\mathrm{sub} / \mathrm{mad}$ & $\operatorname{mad}$ & Small & Absent & 1 & Yes/no \\
\hline+ & Light & $\operatorname{mad}$ & $\operatorname{mad}$ & Normal & Motile & 21 & No \\
\hline+ & Light & $\operatorname{mad}$ & $\operatorname{mad}$ & Normal & Immotile & 23 & No \\
\hline+ & Light & $\operatorname{mad}$ & $\operatorname{mad}$ & $1 \mathrm{~s} / 1 \mathrm{n}$ & Motile & 1 & No \\
\hline \multicolumn{8}{|c|}{$\mathbf{F}_{1}[$ sub $] \times$ sub } \\
\hline$*+$ & Light & $\operatorname{mad}$ & sub & Normal & Immotile & 4 & Yes \\
\hline+ & Light & $\operatorname{mad}$ & sub & Small & Absent & 39 & Yes \\
\hline ve & Dark & sub & sub & Normal & Motile & 37 & No \\
\hline ve & Dark & sub & sub & Normal & Immotile & 39 & No \\
\hline ve & Dark & sub & sub & $1 \mathrm{~s} / 1 \mathrm{n}$ & Motile & 2 & No \\
\hline *ve & Light & $\mathrm{sub} / \mathrm{mad}$ & sub & Small & Absent & 2 & Yes/no \\
\hline$*$ ve & Light & $\mathrm{sub} / \mathrm{mad}$ & sub & Normal & Immotile & 1 & Yes/no \\
\hline
\end{tabular}

$n=$ number of flies examined, Inc. $=$ incompatibility of the sex chromosomes. 
madX flies from those of $\operatorname{madX} /$ subX constitution. The case of males' viability is more clear: backcross males with a madX may have their viability reduced when they carry a subY and the majority of autosomes are of sub origin (Table 6) (the origin of $\mathrm{Y}$ coincides with that of the majority of autosomes).

\section{Extra sex combs}

$\mathrm{F}_{1}$ males from the cross of madeirensis females to subobscura males have extra sex combs, in almost all cases, on the second and sometimes on the third pair of legs. However, the trait's expressivity differs in the repetitions of this cross. Female subobscura crossed to madeirensis males produced males mainly with normal phenotype.

From the results given in Table 7 and summarized in Fig. 1, it seems that the appearance of extra sex combs

Table 5 Female viability is compared to male viability in $F_{1}$ and backcross generations in the two reciprocal crosses. Chisquare testing departure from a 1:1 ratio (1 d.f.) and its significance are given in the last column

\begin{tabular}{llccc}
\hline Generation & Cross & $n$ \% & $n$ ơ $^{*}$ & $\chi^{2}(1$ d.f. $)$ \\
\hline $\mathrm{F}_{1}$ & {$[\mathrm{mad}]$} & 109 & 89 & 2.02 \\
$\mathrm{~B}_{1}$ & $\mathrm{~F}_{1}[\mathrm{mad}] \times \operatorname{mad}$ & 340 & 364 & 0.818 \\
$\mathrm{~B}_{1}$ & $\mathrm{~F}_{1}[\mathrm{mad}] \times \mathrm{sub}$ & 514 & 372 & $22.76^{* * *}$ \\
$\mathrm{~F}_{1}$ & {$[$ sub $]$} & 296 & 360 & $6.24^{* *}$ \\
$\mathrm{~B}_{1}$ & $\mathrm{~F}_{1}[\mathrm{sub}] \times \operatorname{mad}$ & 233 & 290 & $5.99^{*}$ \\
$\mathrm{~B}_{1}$ & $\mathrm{~F}_{1}[\mathrm{sub}] \times \mathrm{sub}$ & 484 & 424 & 3.96 \\
\hline
\end{tabular}

Table 6 Viability of flies with a different genetic constitution to the backcross progenies, classified according to the origin of their X chromosome. Chi-square tests examine the effect of this chromosome on the hybrid viability

\begin{tabular}{llllrc}
\hline Sex & Chromosome & X origin & Y origin & $n$ & $\chi^{2}(1$ d.f. $)$ \\
\hline$\sigma^{*}$ & $\mathrm{~F}_{1}[\mathrm{mad}] \times \mathrm{mad}$ & $\mathrm{mad}$ & $\mathrm{mad}$ & 265 & \\
& & $\mathrm{sub}$ & $\mathrm{mad}$ & 300 & 2.04 \\
$\sigma^{*}$ & $\mathrm{~F}_{1}[\mathrm{mad}] \times \mathrm{sub}$ & $\mathrm{mad}$ & $\mathrm{sub}$ & 84 & \\
& & $\mathrm{sub}$ & $\mathrm{sub}$ & 288 & $111.9 * * *$ \\
& $\mathrm{~F}_{1}[\mathrm{mad}] \times \mathrm{sub}$ & $\mathrm{mad} / \mathrm{sub}$ & - & 239 & \\
& & $\mathrm{sub} / \mathrm{sub}$ & - & 275 & 2.52 \\
$\sigma^{*}$ & $\mathrm{~F}_{1}[\mathrm{sub}] \times \mathrm{mad}$ & $\mathrm{mad}$ & $\mathrm{mad}$ & 142 & \\
& & $\mathrm{sub}$ & $\mathrm{mad}$ & 148 & 0.12 \\
$\mathrm{~F}_{1}$ & $\mathrm{~F}_{1}[\mathrm{sub}] \times \mathrm{mad}$ & $\mathrm{mad}$ & $\mathrm{sub}$ & 56 & \\
& & $\mathrm{sub}$ & $\mathrm{sub}$ & 121 & $23.1 * * *$ \\
& $\mathrm{~F}_{21}[\mathrm{sub}] \times \mathrm{sub}$ & $\mathrm{mad} / \mathrm{sub}$ & - & 74 & \\
& & $\mathrm{sub} / \mathrm{sub}$ & - & 97 & 2.83 \\
\hline
\end{tabular}

${ }^{* *} P<0.01,{ }^{* * *} P<0.001, n=$ total number of emerged flies. mainly depends on the origin of the $\mathrm{X}$ chromosome. Males bearing a madX/subY and a majority of sub autosomes almost always (80-91 per cent) display esc regardless of the origin of their cytoplasm. Males with $\operatorname{madX} / \operatorname{mad} \mathrm{Y}$ and a majority of mad autosomes display the character less frequently; the percentage depends on the origin of the cytoplasm. The appearance of esc phenotypes in the $F_{1}$ of the two reciprocal crosses fits well with the results explained above.

\section{Abnormal head shape}

Several individuals in the $F_{1}$ and the backcross generations display an abnormal head shape. It is clear from the results given in Table 8, that the cytoplasm does not play a role in determining this abnormality in hybrids (e.g. backcross females with $\mathrm{madX} / \mathrm{subX}$ in a mad cytoplasm do not differ from $\operatorname{madX} / \mathrm{subX}$ in a sub cytoplasm). The origin of the $\mathrm{X}$ chromosome(s), however, has a strong effect on the presence of the head abnormality. Females madX/subX show the abnormality much more frequently than those of subX/subX.

In the case of the backcross males the results in Table 8 are summarized in Fig. 2. Head abnormality is displayed more often in individuals with a madX in combination with a $\mathrm{Y}$ and half or the majority of autosomes of subobscura origin.

\section{Abnormalities of abdominal tergites}

These abnormalities comprise all anomalies observed in A1-A8 segments (abdominal tergites). They include the presence of incomplete tergite( $\mathrm{s}$ ), the fusion of two or three tergites, or simply the absence of one or more tergites. It appears from the results given in Table 9 that the $\mathrm{X}$ chromosome does not play any important role in causing this abnormality. Cytoplasmic factor(s) are probably involved. The percentage of abnormal flies increases when mad cytoplasm is substituted by sub cytoplasm. The highest percentages of abnormal tergites occur in the backcross individuals with a sub cytoplasm and the majority of mad chromosomes. This is an indication of a cytoplasm-chromosome interaction.

\section{Discussion}

Seven abnormal characters have been analysed here, six of which are found only in the hybrids; the seventh (abnormal abdominal tergites) is also present in the parental species but with a lower frequency. The existence of these anomalies in the hybrids is an indication of some aberrant developmental process. First we will 
Table 7 Extra sex combs and normals in backcross males are classified according to the origin of their cytoplasm, $\mathrm{Y}$ and $\mathrm{X}$ chromosomes. Chi-square tests compare the difference between the two types of $\mathrm{X}$ chromosome in inducing extra sex combs anomaly in different genetic make ups

\begin{tabular}{|c|c|c|c|c|c|c|c|c|}
\hline Cross & Cytoplasm & $X$ & $\mathrm{Y}$ & Auto. & Esc & $n$ & Percentage esc & $\chi^{2}(1$ d.f. $)$ \\
\hline \multirow[t]{2}{*}{$\mathrm{F}_{1}[\mathrm{mad}] \times \operatorname{mad}$} & $\operatorname{mad}$ & $\operatorname{mad}$ & $\operatorname{mad}$ & $\operatorname{mad}$ & 19 & 107 & 18 & \\
\hline & $\operatorname{mad}$ & sub & $\operatorname{mad}$ & $\operatorname{mad}$ & 10 & 128 & 8 & $5.03^{*}$ \\
\hline \multirow[t]{2}{*}{$F_{1}[\mathrm{mad}] \times \mathrm{sub}$} & $\operatorname{mad}$ & $\mathrm{mad}$ & sub & sub & 45 & 56 & 80 & \\
\hline & $\operatorname{mad}$ & sub & sub & sub & 0 & 165 & 0 & $161.95^{* * *}$ \\
\hline \multirow[t]{2}{*}{$\mathrm{F}_{1}[\mathrm{sub}] \times \mathrm{mad}$} & sub & $\mathrm{mad}$ & $\operatorname{mad}$ & mad & 5 & 164 & 3 & \\
\hline & sub & sub & $\operatorname{mad}$ & $\operatorname{mad}$ & 2 & 150 & 1 & 0.7 \\
\hline \multirow[t]{2}{*}{$\mathrm{F}_{1}[\mathrm{sub}] \times \mathrm{sub}$} & sub & $\mathrm{mad}$ & sub & sub & 72 & 79 & 91 & \\
\hline & sub & sub & sub & sub & 2 & 196 & 1 & $13.5^{* * * *}$ \\
\hline
\end{tabular}

Auto. $=$ majority of autosomes, Esc $=$ extra sex combs, $n=$ total number of flies ${ }^{*} P<0.05,{ }^{* * *} P<0.001$.

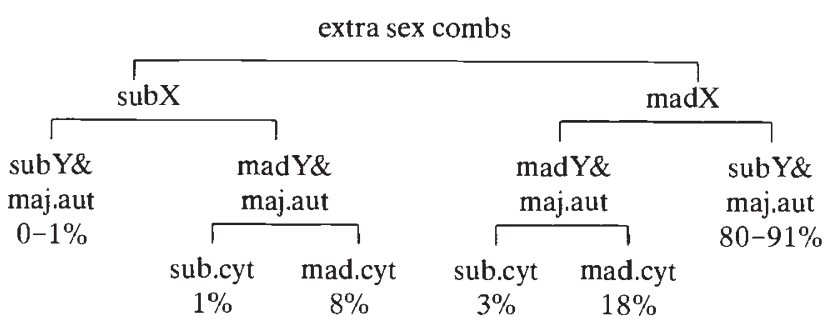

Fig. 1 A classification of the effect of the sex chromosomes, the majority of autosomes and cytoplasm on the extra sex combs phenotype.

discuss the prevalence of Haldane's rule and the effect of the $\mathrm{X}$ chromosome on these characters. Then we will explain the asymmetry observed in the role of the two different $\mathrm{X}$ chromosomes $(\operatorname{madX}$ and subX).

Both Haldane's rule and the X chromosome rule are concerned with sterility/inviability of the hybrids (i.e. fitness). Hybrid sterility agrees with the two rules.

$1 \quad F_{1}$ male sterility is absolute (all males are sterile) but females are partially sterile. This illustrates a partial barrier, i.e. species that have not reached a complete genetic isolation, at least under laboratory conditions.

2 Male sterility appears whenever there is an incompatibility between the sex chromosomes. This type of sterility in the backcross progenies is characterized by the presence of abnormally small testes, usually empty of sperm. When the sex chromosomes are compatible (homospecific) the testes are large and the male may be sterile or fertile, depending on autosomal factors. We have reported on them in detail by examining the backcross males produced by $F_{1}$ [mad] crosses to subobscura males (Khadem \& Krimbas, 1991a). On the other hand, sperm mobility is studied in backcross individuals with a normal testis size, i.e. with compat- ible sex chromosomes. Thus the detection of sex chromosome influence is methodologically excluded. It is quite possible that there are factors on the $\mathrm{X}$ chromosome that determine sperm motility. The near absence of individuals with large testes and incompatible sex chromosomes in the backcross progeny precludes the study of the influence of the $\mathrm{X}$ chromosome on the motility of sperm.

The effect of the $\mathrm{X}$ chromosome was observed in the case of hybrid inviability but Haldane's rule was sometimes violated. Lower viability of the homogametic sex was detected in the $F_{1}$ hybrids from subobscura mothers and also in the progeny of the latter females crossed to madeirensis males. It is mentioned earlier that the extreme case of female lower viability has somehow been modified in the present work. The two stocks of $D$. madeirensis (used in previous studies), when crossed to female subobscura, produced inviable progeny that died as embryos. Males from another stock of $D$. madeirensis, which were used in this sţudy, were crossed to subobscura females that showed a recovery of the $F_{1}$ hybrid females (the sex ratio changed from 5 to 25 or even 50 per cent); the total number of progeny also increased considerably. This system is analogous to the hybrid rescue genes described in the species of the D. melanogaster subgroup (Hutter \& Ashburner, 1987; Hutter et al., 1990). We assume that our new strain of $D$. madeirensis probably carries an allele analogous to $\mathrm{Hmr}$ which enables female hybrids to be rescued. Note that if this assumption is correct, then the gene also rescues some of the hybrid males.

The heterogametic sex suffers a lower viability; when the $\mathrm{F}_{1}$ females from a madeirensis mother were crossed to subobscura males. The large effect of the $\mathrm{X}$ chromosome and deviation from Haldane's rule has been also reported in a cross between $D$. montana and 
Table 8 Flies with abnormal head shape, classified in $\mathrm{F}_{1}$ and the backcross generation according to their cytoplasm and sex chromosomes. Chi-square tests examine the significance of the origin of the $\mathrm{X}$ chromosome in determining the shape of the head in different types of genetic background

\begin{tabular}{|c|c|c|c|c|c|c|c|c|}
\hline Sex & Cross & Cytoplasm & $\mathrm{Y}$ & $X$ & $A$ & $I$ & $\chi^{2}(1$ d.f. $)$ & Percentage \\
\hline o & $F_{1}[\mathrm{mad}]$ & $\operatorname{mad}$ & sub & $\operatorname{mad}$ & 59 & 89 & & 66 \\
\hline o & $\mathrm{F}_{1}[\mathrm{sub}]$ & sub & $\mathrm{mad}$ & sub & 6 & 62 & $49.19^{* * *}$ & 10 \\
\hline$q$ & $\mathrm{~F}_{1}[\mathrm{mad}]$ & $\operatorname{mad}$ & - & $\mathrm{mad} / \mathrm{sub}$ & 73 & 85 & & 86 \\
\hline q & $\mathrm{F}_{1}[\mathrm{sub}]$ & sub & - & $\mathrm{mad} / \mathrm{sub}$ & 74 & 79 & 2.39 & 94 \\
\hline \multirow[t]{2}{*}{ o } & \multirow{2}{*}{$\mathrm{F}_{1}[\mathrm{mad}] \times \mathrm{mad}$} & $\operatorname{mad}$ & $\mathrm{mad}$ & $\operatorname{mad}$ & 28 & 214 & & 13 \\
\hline & & $\mathrm{mad}$ & $\mathrm{mad}$ & sub & 84 & 257 & $23.9^{* * *}$ & 33 \\
\hline \multirow[t]{2}{*}{ o } & \multirow[t]{2}{*}{$\mathrm{F}_{1}[\mathrm{mad}] \times \mathrm{sub}$} & $\operatorname{mad}$ & sub & $\operatorname{mad}$ & 72 & 111 & & 65 \\
\hline & & $\operatorname{mad}$ & sub & sub & 25 & 293 & $147.1^{* * * *}$ & 9 \\
\hline \multirow[t]{2}{*}{0} & \multirow[t]{2}{*}{$\mathrm{F}_{1}[\mathrm{sub}] \times \operatorname{mad}$} & sub & $\operatorname{mad}$ & $\operatorname{mad}$ & 35 & 178 & & 20 \\
\hline & & sub & $\mathrm{mad}$ & sub & 59 & 178 & $8.4^{* *}$ & 33 \\
\hline \multirow[t]{2}{*}{ o } & \multirow[t]{2}{*}{$\mathrm{F}_{1}[\mathrm{sub}] \times$ sub } & sub & sub & $\operatorname{mad}$ & 69 & 114 & & 60 \\
\hline & & sub & sub & sub & 2 & 222 & $149.66^{* * *}$ & 1 \\
\hline \multirow[t]{2}{*}{$q$} & \multirow[t]{2}{*}{$\mathrm{F}_{1}[\mathrm{mad}] \times \mathrm{sub}$} & $\operatorname{mad}$ & - & $\mathrm{mad} / \mathrm{sub}$ & 138 & 176 & & 78 \\
\hline & & $\operatorname{mad}$ & - & sub/sub & 3 & 213 & $247.93^{* * *}$ & 1 \\
\hline \multirow[t]{2}{*}{$q$} & \multirow[t]{2}{*}{$\mathrm{F}_{1}[$ sub $] \times$ sub } & sub & - & $\mathrm{mad} / \mathrm{sub}$ & 87 & 114 & & 76 \\
\hline & & sub & - & sub/sub & 4 & 158 & $160.80^{* * * *}$ & 3 \\
\hline
\end{tabular}

${ }^{* *} P<0.01,{ }^{* * *} P<0.001, A=$ number of abnormal individuals, $T=$ total number of flies examined.

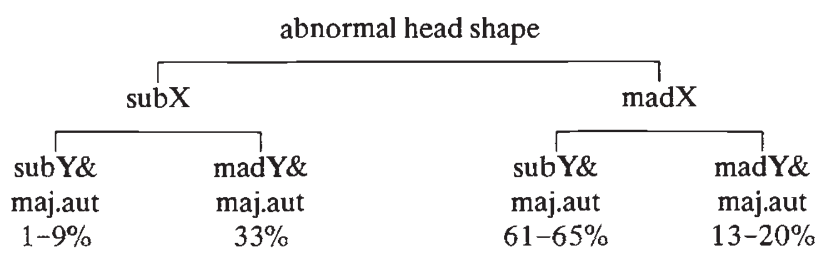

Fig. 2 The effect of the sex chromosomes and the majority of autosomes on head abnormality.

\section{D. americana texana males (Patterson \& Griffen, 1944).}

Previously we reported (Khadem \& Krimbas, 1991b) that the two characters of extra sex combs and abnormal head shape are positively correlated and that there is a close link between these two characters and the sterility/inviability of hybrids. Regardless of the applicability of this to other types of cross, our present data show that the $\mathrm{X}$ chromosome has a strong effect on the determination of these two characters. On the other hand, Haldane's rule is not obeyed with regard to the abnormality of the head shape (extra sex combs is specifically a male character). A head shape abnormality appeared in all the progeny of one of the crosses ( $F_{1}$ progeny of madeirensis mother), and only in $F_{1}$ females of the reciprocal cross (of subobscura females). Curiously it is the same cross in which hybrid viability also deviates from Haldane's rule.
The last character, abnormal abdominal tergites, is rare and it is premature to decide whether the effect of the $\mathrm{X}$ chromosome is really so little, as one of the cases might suggest. Furthermore, because this abnormality has little influence on hybrid fitness (except in a very few cases where many segments are involved) it may not be considered as an exception to the two rules.

In addition to the strong effect of the $\mathrm{X}$ chromosome on some characters (female sterility, male viability, extra sex combs and head shape abnormality), our data show the existence of an asymmetry between the influence of the two Xs (see Figs 1 and 2). In all these cases the madX chromosome has a greater tendency to induce abnormalities. Our unpublished results show that an autosomal factor which affects head and extra sex combs anomalies, interacts with subX in homozygous and with madX either in the homo- or heterozygous state. Therefore, there are more abnormal individuals with madX than there are with subX. How can this asymmetry be explained? One might consider that it is due to chance: when two populations diverge during the speciation process, the chromosome(s) of one population might accumulate those changes that render it (them) incompatible with the genetic background of another. The converse may not be true. Alternatively the original split between the two species may be asymmetric, i.e. only one population of a restricted size isolates itself from other large group of 
Table 9 Percentage of flies with abnormal abdominal tergites in parental species, $\mathrm{F}_{1}$ and backcross hybrids. Chi-square tests show whether the origin of the sex chromosome in determining this anomaly is significant

\begin{tabular}{|c|c|c|c|c|c|c|c|}
\hline Generation & Cross & $X$ & $\begin{array}{l}\text { Y \& majority of } \\
\text { autosomes }\end{array}$ & $A$ & $T$ & $\chi^{2}(1$ d.f. $)$ & Percentage \\
\hline \& P mad & $\operatorname{mad}$ & $\mathrm{mad} / \mathrm{mad}$ & - & 2 & 129 & & 1 \\
\hline O P mad & $\operatorname{mad}$ & $\operatorname{mad}$ & $\operatorname{mad}$ & 2 & 200 & & 1 \\
\hline † P sub & sub & sub/sub & - & 3 & 55 & & 5 \\
\hline o P sub & sub & sub & sub & 3 & 69 & & 4 \\
\hline O $\mathrm{F}_{1}$ & {$[\mathrm{mad}]$} & $\mathrm{mad} / \mathrm{sub}$ & - & 1 & 103 & & 1 \\
\hline$O F_{1}$ & {$[\mathrm{mad}]$} & $\operatorname{mad}$ & sub & 2 & 110 & & 2 \\
\hline \& $\mathrm{B}_{1}$ & $\mathrm{~F}_{1}[\mathrm{mad}] \times \mathrm{mad}$ & mixed & - & 19 & 251 & & 8 \\
\hline \multirow{2}{*}{$O \mathrm{~B}_{1}$} & $\mathrm{~F}_{1}[\mathrm{mad}] \times \mathrm{mad}$ & $\operatorname{mad}$ & $\operatorname{mad}$ & 7 & 112 & & 6 \\
\hline & & sub & $\operatorname{mad}$ & 9 & 144 & 0.00 & 6 \\
\hline \multirow[t]{2}{*}{ \& $\mathrm{B}_{1}$} & $F_{1}[\mathrm{mad}] \times$ sub & $\mathrm{mad} / \mathrm{sub}$ & - & 3 & 76 & & 4 \\
\hline & & sub/sub & - & 3 & 109 & 0.563 & 3 \\
\hline \multirow[t]{2}{*}{$\mathrm{B}_{1}$} & $F_{1}[\mathrm{mad}] \times \mathrm{sub}$ & $\mathrm{mad}$ & sub & 3 & 29 & & 10 \\
\hline & & sub & sub & 4 & 88 & 2.9 & 4 \\
\hline q $F_{1}$ & [sub] & $\mathrm{mad} / \mathrm{sub}$ & - & 8 & 55 & & 14 \\
\hline$O \mathrm{~F}_{1}$ & [sub] & sub & $\operatorname{mad}$ & 15 & 106 & & 14 \\
\hline \& $\mathrm{B}_{1}$ & $\mathrm{~F}_{1}[\mathrm{sub}] \times \mathrm{mad}$ & mixed & - & 29 & 130 & & 22 \\
\hline \multirow[t]{2}{*}{$\sigma \mathrm{B}_{1}$} & $\mathrm{~F}_{1}[\mathrm{sub}] \times \mathrm{mad}$ & $\operatorname{mad}$ & $\operatorname{mad}$ & 20 & 103 & & 16 \\
\hline & & sub & $\operatorname{mad}$ & 22 & 82 & $4.04^{*}$ & 27 \\
\hline \multirow[t]{2}{*}{ क $\mathrm{B}_{1}$} & $\mathrm{~F}_{1}[$ sub] $] \times$ sub & $\mathrm{mad} / \mathrm{sub}$ & - & 1 & 20 & & 5 \\
\hline & & sub/sub & - & 3 & 40 & 0.00 & 7 \\
\hline \multirow[t]{2}{*}{$\mathrm{o}_{1}$} & $\mathrm{~F}_{1}[$ sub] $\times$ sub & $\operatorname{mad}$ & sub & 4 & 13 & & 31 \\
\hline & & sub & sub & 3 & 35 & 3.30 & 9 \\
\hline
\end{tabular}

$A=$ abnormal abnominal tergites, $T=$ total number of flies examined, ${ }^{*} P<0.05$.

populations that occupy an important geographical area. In this case populations of the larger area would change little and would retain most of their original genetic variability. The new species, following its isolation, could undergo a reorganization of the small amount of genetic variability that it contains and be subjected to selective pressures which ensure a fine tuning between its components. It would therefore less easily tolerate foreign genetic material. Here, $D$. madeirensis is the species with the restricted distribution (it is found only in the Madeira island) and is apparently monomorphic for chromosomal inversions, while $D$. subobscura has a much wider geographical distribution and is one of the richest species in inversion polymorphism in its natural populations.

\section{Acknowledgements}

We would like to thank Mrs Georgia Kolia for technical help and Dr E. Zouros for his helpful comments on an earlier version of the manuscript.

\section{References}

CHARLESWORTH, B., COYNE, J. AND BARTON, N. 1987. The relative rates of evolution of sex chromosomes and autosomes. Am. Nat., 130, 113-146.

COYNE, J. A. 1984. Genetic basis of male sterility in hybrids between two closely related species of Drosophila. Proc. Natl Acad. Sci., U.S.A., 81, 4444-4447.

COYNE, J. A. 1985. The genetic basis of Haldane's rule. Nature, 314, 736-738.

COYNE, J. A., CHARLESWORTH, B. AND ORR, H. A. 1991. Haldane's rule revisited. Evolution, 45, 1710-1714.

COYNE, J. A. AND ORR, H. A. 1989. Two rules of speciation. In: Endler, J. A. and Otte, D. (eds) Speciation and Its Consequences, Sinauer Associates, Sunderland, MA.

CROW, J. F. 1942. Cross fertility and isolating mechanisms in the Drosophila melanogaster group. Univ. Texas Publ., 4228, 53-67.

DOBZHANSKY, TH. 1936. Studies on hybrid sterility. ii. Localization of sterility factors in Drosophila pseudoobscura hybrids. Genetics, 21, 113-135.

FRANK, S. A. 1991a. Divergence of meiotic drive-suppression systems as an explanation for sex-biased hybrid sterility and inviability. Evolution, 45, 262-267. 
FRANK, S. A. 1991b. Haldane's rule: A defense of the meiotic drive theory. Evolution, 45, 1714-1717.

HALDANE, J. B. S. 1922 . Sex ratio and universal sterility in animal hybrids. J. Genet., 12, 101-109.

HUTTER, P. AND ASHBURNER, M. 1987. Genetics of inviable hybrids between Drosophila melanogaster and its sibling species. Nature, 327, 331-333.

HUTTER, P., ROOTE, J. AND ASHBURNER, M. 1990. A genetic basis for the inviability of hybrids between sibling species of Drosophila. Genetics, 124, 909-920.

KHADEM, M. AND KRIMBAS, C. B. 1991a. Studies of the species barrier between Drosophila subobscura and D. madeirensis I. The genetics of male hybrid sterility. Heredity, 67, 157-165.

KHADEM, M. AND KRIMBAS, C. B. 1991b. Studies of the species barrier between Drosophila subobscura and D. madeirensis II. Genetic analysis of developmental incompatibility in hybrids. Hereditas, 114, 189-185.

LUMME, J. AND HEIKKIEN, E. 1990. Viability of first and second generation hybrids of Drosophila virilis and Drosophila lummei. Heredity, 65, 435-447.
ORR, H. A. 1987. Genetics of male and female sterility in the hybrids of Drosophila pseudoobscura and D. persimilis. Genetics, 116, 555-563.

ORR, H. A. 1989. Genetics of sterility in hybrids between two subspecies of Drosophila. Evolution, 43, 180-189.

PAPACEIT, M., SAN ANTONIO, J. AND PREVOSTI, A. 1991. Genetic analysis of extra sex combs in hybrids between Drosophila subobscura and D. madeirensis. Genetica, 84, 107-114.

PATTERSON, J. A. AND GRIFFEN, A. B. 1944. A genetic mechanism underlying species isolation. Univ. Texas Publ., 4445, 212-223.

READ, A. AND NEE, S. 1991. Is Haldane's rule significant? Evolution, 45, 1707-1709.

VIGNEAULT, G. AND ZOUROS, E. 1986. The genetics of asymmetrical male sterility in Drosophila mojavensis and Drosophila arizonenesis hybrids: Interaction between the Y chromosome and autosomes. Evolution, 40, 11601170 .

zouros, E. 1986. A model for the evolution of asymmetrical male hybrid sterility and its implications for speciation. Evolution, 40, 1171-1184. 